\title{
Is diabetic retinopathy an inflammatory disease?
}

\section{A P Adamis}

\section{More work remains to prove this hypothesis}

is ast year an ARVO symposium organised by Tim Kern was titled "Is iabetic retinopathy an inflammatory disease?" It is a timely question. chronic subclinical inflammation may underlie much of the vascular pathology of diabetic retinopathy. Nomenclature is critical to this discussion, so the definition of inflammation bears repeating here. Macroscopic inflammation comprises the classic signs of pain (dolor), heat (calor), redness (rubor), swelling (tumor), and loss of function (functio laesa). ${ }^{1}$ None of these signs, except for swelling and loss of function, clearly applies to diabetic retina. However, at a microscopic level, inflammation consists of vessel dilatation, altered flow, exudation of fluids, including plasma proteins, and leucocyte accumulation and migration. ${ }^{1}$ Given the recent data that have been generated in relevant models of diabetic retinopathy, the latter definition appears to fit. A brief overview of the evidence illustrates this point

Within one week of experimental diabetes, leucocytes adhere to and accumulate within the vasculature of the retina. ${ }^{23} \mathrm{~A}$ subset of these leucocytes exit the vasculature and transmigrate into the neural retina. ${ }^{2}$ The leucocyte increases are moderate in nature and precede any overt clinical evidence of retinopathy. However, they progress with time. $^{2}$ Monocytes and neutrophils predominate, ${ }^{4}$ although preliminary data suggest that lymphocytes may be involved as well (Ahmed, Ishida, Adamis, et al, unpublished observation). The leucocytes actively tether themselves to the endothelial cell lining via classic adhesion molecules, including intercellular adhesion molecule-1 (ICAM-1) on the vasculature $^{2}$ and $\beta_{2}$ integrins on the leucocytes. ${ }^{3}$ The expression levels for these adhesion molecules increase in early diabetes and correlate with the leucocyte increases. ${ }^{23}$ Additional adhesion molecules, including vascular cell adhesion molecule-1 (VCAM-1) and VLA-4 may also be involved, but here the data are more preliminary. ${ }^{5}$

The leucocyte increases coincide with the onset of diabetic vascular dysfunction. At first, the dysfunction is subclinical in nature, probably because of the lack of sensitivity of our current clinical detection methods. However, when more powerful experimental techniques are applied, the early alterations uncovered include a subtle breakdown of the blood-retinal barrier, premature endothelial cell injury and death, and capillary ischaemia/reperfusion. ${ }^{26-8}$

The leucocytes appear to be causal for these pathologies. When diabetic rats are treated with ICAM-1 or $\beta_{2}$ integrin neutralising antibodies, leucocyte adhesion is suppressed, ${ }^{23}$ blood-retinal barrier breakdown is normalised, ${ }^{2}$ and endothelial cell injury and death are prevented. When mice deficient in the ICAM-1 or $\beta$ integrin gene CD18 are made diabetic and followed for 11 months, the retinal vasculature is indistinguishable from age matched normal non-diabetic mice (Joussen, Poulaki, Adamis, et al, unpublished data). In contrast, the retinas from diabetic ICAM-1 and CD18 competent mice exhibit marked increases in leucocyte density, blood-retinal barrier breakdown, and endothelial cell injury and death. Since 11 months represents almost half of the normal mouse life span, these data suggest that the inhibition of leucocyte adhesion provides effective long term suppression of certain diabetes related pathologies.

\section{Inflammation may represent the inciting and final common pathway leading to the complex pathology} that is diabetic retinopathy

If diabetic retinopathy is an inflammatory disease, then one would expect that anti-inflammatory drugs would have a beneficial effect. This seems to be the case. In 1964, it was observed that patients with rheumatoid arthritis receiving high doses of aspirin tended to have less severe diabetic retinopathy. ${ }^{9}$ Recently, Kern and Engerman directly tested the effect of aspirin in the relevant dog model of diabetic retinopathy. When started shortly after the onset of diabetes and given for 5 years, aspirin prevented certain classic histopathological features of diabetic retinopathy..$^{10}$ Acellular capillary formation, retinal haemorrhage development, and capillary sudanophilia (a non-specific indicator of cellular degeneration) were all inhibited. A trend towards microaneurysm and pericyte ghost suppression was also observed, although statistical significance was not achieved. The moderately high doses utilised $(20-25 \mathrm{mg} / \mathrm{kg}$ ) were anti-inflammatory in nature and more than twice the antiplatelet dose utilised in the negative Early Treatment Diabetic Retinopathy Study aspirin trial $(650 \mathrm{mg} /$ day) $){ }^{11}$ Recent data in a rodent model complement and extend these findings by showing that a variety of anti-inflammatory drugs can be effective. ${ }^{12}$ High dose aspirin $(50 \mathrm{mg} / \mathrm{kg})$, meloxicam (cyclo-oxygenase-2 inhibitor), and etanercept (soluble tumour necrosis factor $\alpha$ receptor) each potently suppressed diabetic retinal ICAM-1 expression, leucocyte adhesion, and bloodretinal barrier breakdown. Antiinflammatory drug testing in human diabetic retinopathy has begun. Envision, a sustained release formulation of fluocinolone implanted into the vitreous, appears to resolve refractory diabetic macular oedema in early clinical testing (Andrew Pearson, MD, Foundation Fighting Blindness Drug Delivery Meeting, San Francisco, 2001).

How is the slowly evolving nature of diabetic retinopathy reconciled with the finding of early onset inflammation? As noted above, the inflammation is, at first, mild and subclinical in nature. It does not result in an overt vasculitis. However, because the inflammation is chronic in nature, the damage to the vascular endothelium is cumulative. The endothelial cells of the diabetic retinal vasculature proliferate and die at rates much higher than normal..$^{13} 14$ The vascular injury, in large part, is leucocyte induced. ${ }^{8}$ As first proposed by Mizutani and coworkers, ${ }^{14}$ we hypothesise that the chronic low grade endothelial injury of early diabetes is reparable, but as diabetes progresses, the vascular endothelium reaches its Hayflick number and can no longer proliferate and repair the damaged endothelial lining. Acellular capillary formation ensues at this point. We speculate that with the formation of acellular capillaries, irreversible ischaemia develops, leading to marked retinal VEGF upregulation and transition to the proliferative stage of retinopathy.

How is VEGF, a molecule causally linked to the pathogenesis of diabetic retinopathy, connected to the inflammation? It is known that retinal VEGF expression is correlated with diabetic blood-retinal barrier breakdown ${ }^{15-17}$ and ischaemia related neovascularisation in animals $^{1819}$ and humans. ${ }^{20-22}$ Moreover, the inhibition of VEGF prevents these processes in relevant experimental models. ${ }^{17} 1923$ New data now indicate that VEGF can also trigger inflammation. ${ }^{24-27}$ 
In the retina and elsewhere, VEGF can induce ICAM-1 expression and leucocyte adhesion. ${ }^{24-27}$ Further, monocytes, via VEGF receptors on their surfaces, migrate in response to VEGF. ${ }^{28}$ When retinal ICAM-1 bioactivity is blocked, VEGF induced blood-retinal barrier breakdown is almost completely prevented, demonstrating the mechanistic link between the permeability and inflammation enhancing effects of VEGF. ${ }^{26}$ In experimental diabetes, retinal VEGF levels increase within one week. When the endogenous retinal VEGF bioactivity is blocked with a soluble receptor, the ICAM-1 upregulation, leucocyte adhesion, and blood-retinal barrier breakdown are all prevented. ${ }^{172}$ Taken together, these data strongly suggest that retinal VEGF upregulation occurs early in diabetes and serves as an important upstream inducer of early retinal inflammation. What triggers VEGF expression in the first place? There are no definitive answers as yet. However, changes in glucose concentration per se can alter VEGF expression $^{30}$ and may represent a direct proximal upstream stimulus. As diabetes progresses, other stimuli, including advanced glycation end products ${ }^{31}$ and reactive oxygen intermediates, ${ }^{32}$ probably serve to further increase VEGF expression.

How relevant are the experimental data to human diabetic retinopathy? Rodent retinas, although lacking the ability to develop bone fide proliferative diabetic retinopathy, exhibit almost all the biochemical, pathophysiological, and histopathological features of background retinopathy. These include bloodretinal barrier breakdown, altered blood flow, vessel dilatation, microaneurym formation, basement membrane thickening, intraretinal microvascular abnormalities (IRMA), accelerated endothelial cell proliferation and death, pericyte loss, neural cell death, acellular capillary formation, haemorrhage formation, platelet microthrombi, and VEGF upregulation. However, care must to taken when extrapolating data generated in rodents to humans. An ongoing antiICAM-1 trial in Crohn's disease is showing some promise in humans. However, anti-CD18 trials for stroke and myocardial infarction, although supported by rodent data, failed quite spectacularly in humans. Yet the body of correlative evidence in the case of human diabetic retinopathy is greater than that for stroke and myocardial infarction. McLeod and coworkers, in a landmark early study, found a marked increase in leucocyte density and retinal vascular ICAM-1 immunoreactivity in human eyes with diabetic retinopathy. ${ }^{33}$ Others have shown that human diabetic leucocytes are more activated and less deformable, ${ }^{34}$ and that patients with diabetic retinopathy have a more pronounced stimulus induced expression of leucocyte adhesion molecules. ${ }^{33}$ In addition, circulating adhesion molecule levels, shed from activated leucocytes and endothelium, are elevated in patients with progressively worsening retinopathy. ${ }^{35}$ Nevertheless, more evidence is needed.

Taken together, a body of data has been generated indicating that diabetic retinopathy is a low grade inflammatory disease. Inflammation, specifically leucocyte adhesion to the retinal vasculature, may represent the inciting and final common pathway leading to the complex pathology that is diabetic retinopathy. However, more work remains to directly prove this hypothesis, especially in human diabetic retinopathy. The latter, after all, is the only model that really counts.

Br J Ophthalmol 2002;86:363-365

\section{Author's affiliations}

A P Adamis, Massachusetts Eye and Ear Infirmary, 243 Charles Street, Boston MA, 02114, USA; tony_adamis@meei.harvard.edu

\section{REFERENCES}

1 Gallin JI, Snyderman R. Overview. In: Gallin JI, Snyderman R, eds. Inflammation. 3rd ed. Philadelphia: Lippincott Williams \& Wilkins, 1999: 1-4.

2 Miyamoto K, Khosrof S, Bursell SE, et al. Prevention of leukostasis and vascular leakage in streptozotocin-induced diabetic retinopathy via intercellular adhesion molecule-1 inhibition. Proc Natl Acad Sci USA 1999:96: 10836-41.

3 Canas-Barouch F, Miyamoto K, Allport JR, et al. Integrin-mediated neutrophil adhesion and retinal leukostasis in diabetes. Invest Ophthalmol Vis Sci 2000;41:1 153-8

4 Schroder S, Palinski W, Schmid-Schonbein GW. Activated monocytes and granulocytes, capillary nonperfusion, and neovascularization in diabetic retinopathy Am J Pathol 1991;139:81-100.

5 Joussen AM, Huang S, Poulaki V, et al. In vivo retinal gene expression in early diabetes. Invest Ophthalmol Vis Sci 2001;42:3047-57.

6 Miyamoto K, Hiroshiba N, Tsujikawa A, et al. In vivo demonstration of increased leukocyte entrapment in retinal microcirculation of diabetic rats. Invest Ophthalmol Vis Sci 1998;39:2190-4

7 Xu Q, Qaum T, Adamis AP. Sensitive blood-retinal barrier breakdown quantitation using Evans blue. Invest Ophthalmol Vis Sci 2001;42:789-94.

8 Joussen AM, Murata T, Tsujikawa A, et al. Leukocyte-mediated endothelial cell injury and death in the diabetic retina. Am J Pathol 2001;158:147-52.

9 Powell EDU, Field RA. Diabetic retinopathy in rheumatoid arthritis. Lancet 1964; 2:17-18.

10 Kern TS, Engerman RL. Pharmacological inhibition of diabetic retinopathy: aminoguanidine and aspirin. Diabetes 2001;50:1636-42.

11 Early Treatment Diabetic Retinopathy Study. Effects of aspirin treatment on diabetic retinopathy. ETDRS report number 8 . Ophthalmology 1991:98;757-65.

12 Joussen AM, Poulaki V, Mitsiades N, et al. Non-steroidal anti-inflammatory drugs prevent early diabetic retinopathy via TNF-alpha suppression. FASEB J 2002; (in press).
13 Sharma NK, Gardiner TA, Archer DB. A morphologic and autoradiographic study of cell death and regeneration in the retinal microvasculature of normal and diabetic rats. Am J Ophthalmol 1985;100:51-60.

14 Mizutani M, Kern TS, Lorenzi M. Accelerated death of retinal microvascular cells in human and experimental diabetic retinopathy. J Clin Invest 1996:97:2883-90.

15 Murata T, Ishibashi T, Khalil A, et al. Vascular endothelial growth factor plays a role in hyperpermeability of diabetic retina vessels. Ophthalmic Res 1995;27:48-52.

16 Vinores SA, Youssri Al, Luna JD, et al. Upregulation of vascular endothelial growth factor in ischemic and non-ischemic human and experimental retinal disease. Histol Histopath 1997; 12:99-109.

17 Qaum T, Xu Q, Joussen AM, et al. VEGF-initiated blood-retinal barrier breakdown in early diabetes. Invest Ophthalmol Vis Sci 2002;42:2408-13.

18 Miller J, Adamis AP, Shima DT, et al. Vascular endothelial growth factor/vascular permeability factor is temporally and spatially correlated with ocular angiogenesis in a primate model. Am J Pathol 1994; 145:574-84.

19 Aiello LP, Pierce EA, Foley ED, et al. Suppression of retinal neovascularization in vivo by inhibition of vascular endothelial growth factor (VEGF) using soluble VEGF-receptor chimeric proteins. Proc Natl Acad Sci USA 1995;92:10457-61.

20 Adamis AP, Miller J, Bernal M-T, et al. Increased vascular endothelial growth factor levels in the vitreous of eyes with proliferative diabetic retinopathy. Am J Ophthalmol 1994; 118:445-50

21 Aiello LP, Avery RL, Arrigg PG, et al. Vascular endothelial growth factor in ocular fluid of patients with diabetic retinopathy and other retinal disorders. N Engl J Med 1994;331:1480-7.

22 Malecaze F, Clamens S, Simorre-Pinatel V, et al. Detection of vascular endothelial growth factor messenger RNA and vascular endothelial growth factor-like activity in proliferative diabetic retinopathy. Arch Ophthalmol 1994;112:1476-82.

23 Adamis AP, Shima DT, Tolentino M, et al. Inhibition of vascular endothelial growth factor prevents retinal ischemia-associated iris neovascularization in a nonhuman primate. Arch Ophthalmol 1996;1 14:66-71.

24 Melder RJ, Koenig GC, Witwer BP, et al. During angiogenesis, vascular endothelial growth factor and basic fibroblast growth factor regulate natural killer cell adhesion to tumor endothelium. Nat Med 1996;2:992-7.

25 Detmar M, Brown LF, Schon MP, et al. Increased microvascular density and enhanced leukocyte rolling and adhesion in the skin of VEGF transgenic mice. J Invest Dermatol 1998;111:1-6.

26 Miyamoto K, Khosrof S, Bursell S-E, et al. Vascular endothelial growth factor-induced retinal vascular permeability is mediated by intercellular adhesion molecule-1 (ICAM-1). Am J Pathol 2000;156:1733-9.

27 Lu M, Perez V, Ma N, et al. VEGF increases retinal vascular ICAM-1 expression in vivo. Invest Ophthalmol Vis Sci 1999;40: 1808-12.

28 Clauss $M$, Gerlach M, Gerlach $\mathrm{H}$, et al. Vascular permeability factor: a tumor-derived polypeptide that induces endothelial cell and monocyte procoagulant activity, and promotes monocyte migration. J Exp Med 1990; 172:1535-45.

29 Joussen AM, Poulaki V, Qin W, et al. Retinal VEGF induces ICAM- 1 and eNOS expression and initiates diabetic retinal leukocyte adhesion in vivo. Am J Pathol 2002;160 501-9.

30 Shweiki D, Neeman $M$, Itin A, et al. Induction of vascular endothelial growth factor expression by hypoxia and by glucose deficiency in multicell spheroids: implications for tumor angiogenesis. Proc Natl Acad Sci USA 1995;92:768-72. 
31 Lu M, Kuroki M, Amano S, et al. Advanced glycation end products increase retinal vascular endothelial growth factor expression. J Clin Invest 1998;101:1219-24.

32 Kuroki M, Voest EE, Amano S, et al. Reactive oxygen intermediates increase vascular endothelial growth factor expression in vitro and in vivo. J Clin Invest 1996:98: 495-504.
33 McLeod DS, Lefer DJ, Merges C, et al. Enhanced expression of intracellular adhesion molecule- 1 and P-selectin in the diabetic human retina and choroid. Am J Pathol 1995; 147:642-53.

34 Pecsvarady Z, Fisher TC, Darwin CH, et al. Decreased polymorphonuclear leukocyte deformability in NIDDN. Diabetes Care 1994;17:57-63.
35 Rao KM, Hatchell DL, Cohen $\mathrm{HJ}$, et al. Alterations in stimulus-induced integrin expression in peripheral blood neutrophils of patients with diabetic retinopathy. Am J Med Sci 1997;313:131-7.

36 Olson JA, Whitelaw CM, McHardy KC, et al. Soluble leucocyte adhesion molecules in diabetic retinopathy stimulate retinal endothelial cell migration. Diabetologia 1997:40:1166-71.

\section{Blood pressure control and diabetic retinopathy}

\section{R Klein, B E K Klein}

\section{New insights}

t is nearly 25 years since the Diabetic Retinopathy Study, a multicentred controlled clinical trial, first reported the efficacy of treatment by photocoagulation of proliferative diabetic retinopathy with high risk characteristics for visual loss. ${ }^{1}$ In 1985, the Early Treatment Diabetic Retinopathy Study (ETDRS) demonstrated the beneficial effects of focal laser treatment for clinically significant macular oedema in patients with diabetes. ${ }^{2}$ Based on data from these studies, it was estimated that timely detection and photocoagulation treatment of vision threatening retinopathy could prevent nearly $95 \%$ of severe visual loss in patients with diabetes. ${ }^{3}$ Despite the resulting development of guidelines and education and screening programmes for early detection and treatment of these problems, diabetic retinopathy still remains an important cause of visual loss. ${ }^{4-6}$ More recently, the Diabetes Control and Complications Trial $(\mathrm{DCCT})^{7-12}$ and the United Kingdom Prospective Diabetes Study (UKPDS) $)^{13-15}$ have demonstrated the efficacy and cost effectiveness of glycaemic control in reducing the incidence and progression of retinopathy. However, data from these and other studies ${ }^{12} 1617$ have confirmed how difficult it is to achieve and maintain good glycaemic control over a long period. For this reason, intervention on other risk factors such as hypertension have been studied in an effort to decrease the risk of visual loss due to diabetic retinopathy. The purpose of this commentary is to briefly describe new findings regarding the role of blood pressure control in the prevention of visual loss in people with diabetes and to review whether specific classes of antihypertensive medications are associated with reduced incidence and progression of retinopathy even in normotensive people with diabetes.

\section{IS BLOOD PRESSURE ASSOCIATED WITH DIABETIC RETINOPATHY AND MACULAR OEDEMA?}

Increased blood pressure has been hypothesised, through the effects of increased blood flow, to damage the retinal capillary endothelial cells in eyes of people with diabetes. ${ }^{18}$ This hypothesis has been supported by observations from clinical studies which showed an association between hypertension and the presence and severity of retinopathy in people with diabetes. ${ }^{19-22}$

While cross sectional data suggest that hypertension is associated with diabetic retinopathy, longitudinal data have been inconsistent. ${ }^{23-30}$ The UKPDS showed that the incidence of retinopathy was associated with systolic blood pressure. ${ }^{30}$ Of the 1919 patients with older onset (type 2) diabetes from that study with retinal photographs taken at diagnosis and 6 years later, systolic blood pressure was significantly associated with retinopathy incidence (type 2). Those in the top tertile range at baseline (systolic blood pressure $\geqslant 140 \mathrm{~mm} \mathrm{Hg}$ ) were 2.8 times ( $95 \%$ confidence interval) as likely to develop retinopathy as people in the lowest tertile range (systolic blood pressure $<125 \mathrm{~mm}$ $\mathrm{Hg}$ ). There was no relation of systolic blood pressure at baseline with retinopathy progression. In the Wisconsin Epidemiologic Study of Diabetic Retinopathy (WESDR), diastolic blood pressure was a significant predictor of progression of diabetic retinopathy to proliferative diabetic retinopathy over 14 years of follow up in patients with younger onset (type 1) diabetes mellitus, independent of glycosylated haemoglobin and the presence of gross proteinuria. ${ }^{31}$ However, neither systolic or diastolic blood pressure nor hypertension at baseline were associated with the incidence and progression of retinopathy in people with type 2 diabetes mellitus. ${ }^{32}$ In the WESDR, patients with older onset diabetes with high blood pressure and retinopathy were at a higher risk of death than people with high blood pressure without retinopathy, and the inability to find a relation between progression of retinopathy and blood pressure may have been due, in part, to this selective mortality. However, diastolic blood pressure in the fourth quartile range was found to be associated with a $330 \%$ increased 4 year risk of developing macular oedema compared to the first quartile range in those with younger onset diabetes mellitus and a $210 \%$ increased risk in those with older onset diabetes in that study. ${ }^{33}$

\section{DOES CONTROL OF BLOOD PRESSURE REDUCE THE RISK OF INCIDENCE AND PROGRESSION OF RETINOPATHY? IF SO, IS THE TYPE OF MEDICATION USED TO CONTROL BLOOD PRESSURE IMPORTANT?}

Results from three clinical trials have recently been published regarding the association of blood pressure control and type of antihypertensive medication used with the incidence and progression of retinopathy. ${ }^{34-38}$ The EURODIAB Controlled Trial of Lisinopril in Insulin Dependent Diabetes Mellitus (EUCLID) Study sought to examine the role of an angiotensin converting enzyme (ACE) inhibitor in reducing the incidence and progression of retinopathy. ${ }^{34}$ The subjects included a group of largely normotensive younger onset diabetic patients of whom $85 \%$ did not have microalbuminuria at baseline. The study showed a statistically significant $50 \%$ reduction in the progression of retinopathy in those taking lisinopril over a 2 year period compared to those not on blood pressure medication, after adjustment for glycaemic control. Progression to proliferative retinopathy was also reduced by $82 \%$ in the group taking lisinopril compared to the group treated with the placebo. After controlling for study site, the difference between treatment groups was no longer statistically significant $(p=0.06)$. There was no significant interaction with blood glucose control. It has been postulated that ACE inhibitors, such as lisinopril, might have an effect independent of blood pressure lowering through a number of possible mechanisms which included a beneficial haemodynamic effect, enhancement of nitric 
oxide resulting in a reduction of endothelial dysfunction, blockage of induction of vascular endothelial growth factor receptors, and reduction of metalloproteinase activity improving the blood-retinal barrier. ${ }^{39}$ It may also be true that higher blood pressure, even in the "normal range," is still associated with risk, and thus lowering blood pressure at all levels might be beneficial to the retina. This is consistent with observations from the UKPDS which reported that there was no evidence of a threshold effect of systolic blood pressure for the incidence of microvascular complications in people with type 2 diabetes mellitus. ${ }^{36}$

The UKPDS also sought to determine whether lower blood pressure achieved with either a $\beta$ blocker or an ACE inhibitor was beneficial in reducing macrovascular and microvascular complications associated with type 2 diabetes mellitus. ${ }^{37} \mathrm{~A}$ total of 1048 patients with hypertension (mean blood pressure 160/94 mm Hg) were randomised to a regimen of tight control of blood pressure with either captopril or atenolol and another 390 patients to less tight control. The aim in the group randomised to tight control was to achieve blood pressure values $<150 /<85$ $\mathrm{mm} \mathrm{Hg}$. If these goals were not met with maximal doses of a $\beta$ blocker or ACE inhibitor, additional medications were prescribed, including a loop diuretic, a calcium channel blocker, and a vasodilator. The aim in the "control" or conventionally treated group was to achieve blood pressure values $<180 /<105 \mathrm{~mm}$ Hg. Tight blood pressure control resulted in a $35 \%$ reduction in retinal photocoagulation compared to conventional control. After 7.5 years of follow up, there was a $34 \%$ reduction in the rate of progression of retinopathy by two or more steps using the modified ETDRS severity scale and a $47 \%$ reduction in the incidence of deterioration of visual acuity by three lines or more using the ETDRS charts (for example, a reduction in vision from 20/30 to $20 / 60$ or worse on a Snellen chart). It is assumed that the effect was largely due to a reduction in the incidence of diabetic macular oedema. Atenolol and captopril were equally effective in reducing the risk of developing these retinal microvascular complications. The effects of blood pressure control were independent of those of glycaemic control. These findings support the recommendations for tight blood pressure control in patients with type 2 diabetes mellitus as a means of preventing visual loss from diabetic retinopathy.

The Appropriate Blood Pressure Control in Diabetes (ABCD) Trial was a prospective randomised masked clinical trial comparing the effects of intensive (diastolic blood pressure goal of $75 \mathrm{~mm}$ $\mathrm{Hg}$ ) and moderate (diastolic blood pressure of $80-89 \mathrm{~mm} \mathrm{Hg}$ ) blood pressure control in 470 hypertensive subjects (baseline diastolic blood pressure of $\geqslant 90$ mm $\mathrm{Hg}$ ) with type 2 diabetes mellitus. ${ }^{38}$ People were randomised to nisoldipine 10 $\mathrm{mg} /$ day (titrated up to $60 \mathrm{mg} /$ day as needed), enalapril $5 \mathrm{mg}$ /day (titrated up to $40 \mathrm{mg}$ /day as needed), or placebo as the initial hypertensive medication. ${ }^{38}$ If single study medication alone did not achieve the target blood pressure, then metoprolol followed by hydrochlorothiazide was added until the target blood pressure was achieved. The mean blood pressure achieved was 132/78 $\mathrm{mm} \mathrm{Hg}$ in the intensive group and 138/86 $\mathrm{mm} \mathrm{Hg}$ in the moderate control group. Over a 5 year follow up period, there was no difference between the intensive and moderate groups with regard to progression of diabetic retinopathy. There was no difference in nisoldipine versus enalapril in progression of retinopathy. The authors concluded that lack of efficacy in their study compared to the UKPDS might have resulted from the shorter time period of the ABCD trial ( 5 years versus 9 years on average for the UKPDS), lower average blood pressure control in the $\mathrm{ABCD}$ trial (144/82 mm Hg versus 154/87 mm Hg in the UKPDS), and poorer glycaemic control in the ABCD trial than the UKPDS. It is possible that there is a threshold effect below which there is no or minimal effect of reducing the risk of progression of retinopathy by further reduction of blood pressure. Results from other clinical trials that are currently under way should provide more information regarding the relative efficacy of blood pressure control and specific antihypertensive medications in reducing the progression of retinopathy in people with diabetes.

\section{CONCLUSIONS}

Hypertension in people with diabetes is common, affecting 30\% of people with younger onset diabetes mellitus and 75\% with older onset diabetes mellitus (Klein $\mathrm{R}$, unpublished data). It is often poorly controlled with only about $60 \%$ of those with younger onset diabetes mellitus and $42 \%$ of those with older onset diabetes mellitus achieving normal blood pressure (Klein R, unpublished data). While observational longitudinal data show an association of blood pressure with long term incidence and progression of retinopathy, there is no clinical trial evidence that blood pressure control prevents the incidence and progression of retinopathy in those with type 1 diabetes mellitus. The data for people with type 2 diabetes mellitus are not consistent. The efficacy of blood pressure control for retinopathy in people with hypertension and diabetes may be a moot point because of the known serious systemic sequelae (for example, higher risk of cardiovascular disease, nephropathy, and amputation) of uncontrolled hypertension. For these reasons the American Diabetes Association has issued guidelines for targeted systolic blood pressure levels of $<130 \mathrm{~mm}$ $\mathrm{Hg}$ and diastolic blood pressure levels of $<85 \mathrm{~mm} \mathrm{Hg} .^{40}$ Whether lowering of blood pressures already in the normal range is beneficial, is still unknown.

An important unanswered question is: do specific types of antihypertensive agents, such as ACE inhibitors, have a beneficial effect in preventing the incidence and progression of retinopathy in diabetic people who are normotensive? The EUCLID data are suggestive for people with type 1 diabetes mellitus, but the findings are not conclusive owing to the small sample size in that study. ${ }^{34}$ The UKPDS data show no difference in the efficacy of ACE inhibitors and $\beta$ blockers with regard to retinopathy progression in people with type 2 diabetes mellitus, suggesting that blood pressure lowering and not the type of medication was more important in people with moderately severe hypertension. ${ }^{37}$ Thus, ophthalmologists at this point should not be recommending a specific type of antihypertensive medication, such as ACE inhibitors, be used for reducing the risk of progression of diabetic retinopathy in normotensive individuals. These medications may be costly and are not without risk. However, for diabetic people with cardiovascular disease, microalbuminuria, or nephropathy, this too may be a moot point. Data from the Heart Outcomes Prevention Evaluation (HOPE) study showed that ramipril, an ACE inhibitor, substantially lowered the risk of death from cardiovascular disease by $37 \%$, stroke by $33 \%$, myocardial infarction by $22 \%$, need for revascularisation procedure by $17 \%$, and overt nephropathy by $24 \%$ in a group of diabetic patients $(n=3577$, of whom 56\% had known hypertension) participating in that study. ${ }^{42}$ These findings resulted despite a very small reduction in blood pressure. A large randomised controlled clinical trial, the DIRECT study, has just begun with its major objective to examine the efficacy of use of ACE inhibitors to prevent incidence and progression of retinopathy in people with type 1 and type 2 diabetes mellitus.

\section{ACKNOWLEDGEMENTS}

This research is supported by National Institutes of Health grants EYO3083, EY12198, and NL59259. RK is a member of the Steering Committee of the DIRECT trial sponsored by Astra-Zeneca.

Br J Ophthalmol 2002;86:365-367

\section{Authors' affiliations}

R Klein, B E K Klein, Department of Ophthalmology and Visual Sciences, University of Wisconsin-Madison, 610 North Walnut Street, 460 WARF, Madison, WI 53705-2397, USA

Correspondence to: Ronald Klein kleinr@epi.ophth.wisc.edu 


\section{REFERENCES}

1 Diabetic Retinopathy Study Research Group. Preliminary report on effects of photocoagulation therapy. Am J Ophthalmol 1976;81:383-96.

2 ETDRS Research Group. Photocoagulation for diabetic macular edema. Arch Ophthalmol 1985:103:1796-806.

3 Ferris FL III. How effective are treatments for diabetic retinopathy? JAMA 1993;269:1290-1.

4 International Diabetes Federation. Diabetes care and research in Europe: the Saint Vincent Declaration. Diabet Med 1990;7:360.

5 The National Eye Health Education Program. From Vision Research to Eye Health Education: Planning the Partnership. Bethesda, MD: National Institutes of Health; March 1990. Available from National Institutes of Health, Box 20/20, Bethesda, MD 20892.

6 American Diabetes Association. Diabetic retinopathy. Position statement. Diabetes Care 1998:21:157-9.

7 The Diabetes Control and Complications Trial Research Group. The effect of intensive treatment of diabetes on the development and progression of long-term complications in insulin-dependent diabetes mellitus. N Engl J Med 1993;329:977-86.

8 The Diabetes Control and Complications Trial Research Group. The effect of intensive diabetes treatment on the progression of diabetic retinopathy in insulin-dependent diabetes mellitus: the Diabetes Control and Complications Trial. Arch Ophthalmol 1995;113 36-51.

9 The Diabetes Control and Complications Trial Research Group. Progression of retinopathy with intensive versus conventional treatment in the Diabetes Control and Complications Trial. Ophthalmology 1995; 102:647-61

10 The Diabetes Control and Complications Trial Research Group. The absence of a glycemic threshold for the development of long-term complications: the perspective of the Diabetes Control and Complications Trial. Diabetes 1996;45: 1289-98.

11 The Diabetes Control and Complications Trial Research Group. Lifetime benefits and costs of intensive therapy as practiced in the Diabetes Control and Complications Trial. JAMA 1996;276:1409-15.

12 The Diabetes Control and Complications Trial/Epidemiology of Diabetes Interventions and Complications Research Group. Retinopathy and nephropathy in patients with type 1 diabetes four years after a trial of intensive therapy. N Engl J Med 2000;342:381-9.

13 UK Prospective Diabetes Study Group. Intensive blood-glucose control with sulphonylureas or insulin compared with conventional treatment and risk of complications in patients with type 2 diabetes (UKPDS 33). Lancet 1998;352:837-53.
14 UK Prospective Diabetes Study Group. Effect of intensive blood-glucose control with metformin on complications in overweight patients with type 2 diabetes (UKPDS 34). Lancet 1998:352:854-65.

15 Gray A, Raikou M, McGuire A, et al. Cost effectiveness of an intensive blood glucose control policy in patients with type 2 diabetes: economic analysis alongside randomised controlled trial (UKPDS 41). BM 2000:320:1373-8.

16 Harris MI. Health care and health status and outcomes for patients with type 2 diabetes. Diabetes Care 2000;23:754-8.

17 Klein R, Klein BEK, Moss SE, et al. The medical management of hyperglycemia over a 10-year period in people with diabetes. 10-year period in people with diabetes Care 1996;19:44-50.

18 Kohner EM. Diabetic retinopathy. Br Med Bull 1989;45: 148-73

19 Davis MD. Diabetic retinopathy, diabetic control, and blood pressure. Transplant Proc 1986; 18:1565-8

20 Fujisawa T, Ikegami $\mathrm{H}$, Yamato $\mathrm{E}$, et al. Association of plasma fibrinogen level and blood pressure with diabetic retinopathy and renal complications associated with proliferative diabetic retinopathy in type II diabetes mellitus. Diabet Med 1999; 16:522-6

21 Chase HP, Garg SK, Jackson WE, et al. Blood pressure and retinopathy in type 1 diabetes. Ophthalmology 1990;97:155-9.

22 Gillow JT, Gibson JM, Dodson PM Hypertension and diabetic retinopathy-what's the story? $\mathrm{Br}$ Ophthalmol 1999:83:1083-7.

23 Norgaard K, Feldt-Rasmussen B, Deckert T. Is hypertension a major independent risk factor for retinopathy in type 1 diabetes. Diabetic Med 1991;8:334-7

24 Teuscher A, Schnell H, Wilson PWF. Incidence of diabetic retinopathy and relationship to baseline plasma glucose and blood pressure. Diabetes Care 1988; 11:246-51

25 Haffner SM, Fong D, Stern MP, et al. Diabetic retinopathy in Mexican Americans and non-Hispanic whites. Diabetes 1988;37:878-84

26 Hamman RF, Mayer EJ, Moo-Young GA, et al. Prevalence and risk factors of diabetic retinopathy in non-Hispanic whites and Hispanics with NIDDM San Luis Valley Diabetes Study. Diabetes 1989;38:1231-7.

27 Kostraba JN, Klein R, Dorman JS, et al. The Epidemiology of Diabetes Complications Study. IV. Correlates of diabetic background and proliferative retinopathy. Am J Epidemiol 1991;133:381-91.

28 Ballard DJ, Melton LJ, Dwyer MS, et al. Risk factors for diabetic retinopathy: a population-based study in Rochester Minnesota. Diabetes Care 1986;9:334-42.

29 Klein R, Klein BEK. Vision disorders in diabetes. In: Hammon R, Harris MWH, eds. Diabetes in America, Diabetes Data Compiled 1984. Bethesda, MD: US Public Health
Service, NIH Publication No 85-1468.

Chapter XIII, August 1985:1-36.

30 Stratton IM, Kohner EM, Aldington SJ, et al. UKPDS 50: risk factors for incidence and progression of retinopathy in type II diabetes over 6 years from diagnosis. Diabetologia 2001;44:156-63.

31 Klein R, Klein BEK, Moss SE, et al. The Wisconsin Epidemiologic Study of Diabetic Retinopathy. XVII. The 14-year incidence and progression of diabetic retinopathy and associated risk factors in type 1 diabetes. Ophthalmology 1998;105:1801-15

32 Klein R, Klein BEK, Moss SE, et al. Is blood pressure a predictor of the incidence or progression of diabetic retinopathy? Arch Intern Med 1989;149:2427-32

33 Klein R, Moss SE, Klein BEK, et al. The Wisconsin Epidemiologic Study of Diabetic Retinopathy. XI. The incidence of macular edema. Ophthalmology 1989;96:1501-10.

34 Chaturvedi N, Sjolie AK, Stephenson JM, et al. Effect of lisinopril on progression of retinopathy in normotensive people with type 1 diabetes. The EUCLID Study Group. EURODIAB Controlled Trial of Lisinopril in Insulin-Dependent Diabetes Mellitus. Lancet 1998;351:28-31.

35 Chaturvedi N. Modulation of the renin-angiotensin system and retinopathy. Heart 2000;84:i29-i31.

36 Adler A, Stratton IM, Neil HAW, et al. Association of systolic blood pressure with macrovascular and microvascular complications of type 2 diabetes (UKPDS 36): prospective observational study. BM 2000;31:412-19.

37 UK Prospective Diabetes Study Group. Tight blood pressure control and risk of macrovascular and microvascular complications in type 2 diabetes (UKPDS 38). BM 1998;317:703-13.

38 Estacio RO, Jeffers BW, Gifford N, et al. Effect of blood pressure control on diabetic microvascular complications in patients with hypertension and type 2 diabetes. Diabetes Care 2000:23:B54-64

39 Deinum J, Chaturvedi N. The renin-angiotensin system and vascular disease in diabetes. Seminars in Vascular Medicine. ATVB 2001 ; (in press)

40 American Diabetes Association. Clinical practice recommendations 1995: position statement: standards of medical care for patients with diabetes mellitus. Diabetes Care $1995 ; 18: 8-15$.

41 The Heart Outcomes Prevention Evaluation Study Investigators. Effects of an angiotensin-converting-enzyme inhibitor, ramipril, on cardiovascular events in high-risk patients. N Engl J Med 2000;342: 145-53.

42 The Heart Outcomes Prevention Evaluation Study Investigators. Effects of ramipril on cardiovascular and microvascular outcomes in peopole with diabetes mellitus: results of the HOPE study and MICRO-HOPE substudy. Lancet 2000;355:253-9. 


\section{Anti-angiogenic therapy for uveal melanoma-more haste, less speed}

\section{A W Stitt, T A Gardiner}

\section{Tumour angiogenesis is a key concept that supports investigations in a range of clinically relevant research areas}

$\mathrm{V}$ ascularisation is critical for the support of substantial tumour growth. For a wide range of tumours, a complex microvasculature accompanies the transition from hyperplasia to neoplasia, a progression from low to high grade classification and enhanced metastatic capacity. The pioneering work of Folkman and Warren and Shubik outlined the critical importance of "tumour angiogenesis" to an initially sceptical field as far back as the late 1960s. ${ }^{12}$ Folkman's struggle to have this hypothesis supported has been recently portrayed in a fine biography by Robert Cooke. ${ }^{3}$ Thirty years on, it is now accepted that most tumours require a complex microvasculature in order to grow beyond approximately $1-2 \mathrm{~mm}$ in diameter. The belief that their essential, and potentially labile, vascular supply represents a chink in the tumour armour has precipitated an ever growing raft of research. Indeed, tumour angiogenesis is a key concept that supports investigations in a range of clinically relevant research areas such as the diagnosis and prognosis of cancers, discovery and molecular characterisation of new angiogenic factors, the identification and therapeutic potential of endogenous anti-angiogenic agents, and characterisation of tumour specific vascular markers.

Pathogenic angiogenesis is a well known phenomenon to ophthalmologists and vision scientists since it is the underlying basis of many important ocular diseases such as retinopathy of prematurity, proliferative diabetic retinopathy, and the wet form of age related macular degeneration. Not surprisingly, angiogenesis is also thought to be a central event in growth of ocular neoplasms, none more so than uveal melanomas, where a high tumour vascularity index carries increased risk of metastasis and poor prognostic outcome. They are also known to precipitate secondary neovascularisation of the retina and iris. However, there are significant and extensive gaps in our knowledge of uveal melanomas and their secondary effects. We are still seeking answers to key questions such as what exactly is the cellular and molecular basis of angiogenic growth in these tumours, how does this affect remote, non-involved ocular tissues such as the retina, and what target(s) represent the best therapeutic options for future development?

\section{Angiogenesis is ... thought to be a central event in growth of ocular neoplasms... where a high tumour vascularity index carries increased risk of metastasis and poor prognostic outcome}

In this issue of the $B J O$, Boyd et al (pp 440 and 448) present data that confirm an important role for vascular endothelial growth factor-A (VEGF-A) and, to a lesser extent, basic fibroblast growth factor (bFGF) in angiogenic growth in and around uveal melanomas. Using a range of approaches, they assayed these factors in ocular fluids and postmortem specimens from patients, grew co-cultures of tumour cells and endothelium in vitro, and concluded that anti-angiogenic therapy may be a worthwhile approach for treatment of eyes harbouring uveal melanomas. In many of these tumours VEGF-A was expressed at high levels, and this was especially true in patients who developed secondary retinal and iris neovascularisation following ionising radiation treatment of their tumours. VEGF-A expression was shown to be particularly high in the ocular fluids of this subset of patients and Boyd et al conclude that this phenomenon makes the case for antiVEGF-A treatment as an adjunctive therapy in the treatment of uveal melanoma and secondary neovascularisation. While this may be so, the authors acknowledge that the situation is still extremely complex and interpatient variability remains surprisingly high. Furthermore, it should be considered that increased levels of VEGF following irradiation of the tumour could represent a classic response to tissue hypoxia following enhanced destruction of vascular endothelial cells that, in the case of melanoma, may be more radiosensitive than the tumour they serve.
While anti-angiogenic therapies continue to be developed at an ever increasing pace, it is perhaps worth considering the pros and cons of such approaches. As a case in point, uveal melanomas carry a serious risk of metastasis and enucleation remains a necessary, if last resort, option. Therefore, there are real pressures to take radical steps that may reduce growth and metastatic potential of these aggressive tumours and prevent secondary neovascularisation. Agents such as anti-VEGF antibodies, VEGF receptor or integrin antagonists, VEGF aptamers, matrix metalloproteinase (MMP) inhibitors, antisense oligonucleotides to growth factor mRNAs, and established drugs such as thalidomide are already in various stages of clinical trial and may offer therapeutic benefits. Given the proliferation of these anti-angiogenics and the prolonged nature of many trials we will soon discover the validity of such an approach. However, it should be considered that growth factors such as VEGF-A represent single members of highly complex and interrelated families, many of which can also contribute to ocular angiogenesis. Even more importantly, many of these peptides are proved survival factors, especially in the retinal microvasculature. ${ }^{45}$ and their effective depletion in a delicately balanced system could have serious long term and unwanted vasodegenerative effects in non-target tissue.

Another potentially negative consequence of an anti-angiogenic strategy for uveal melanomas and/or secondary neovascularisation, especially as an adjunct to radiation therapy, may be the inadvertent promotion of a more aggressive tumour phenotype. It has been demonstrated in various malignant tumours that induction of hypoxia, by restricting vascular supply, may actually promote selection of hypoxia resistant tumour cells with decreased apoptotic potential. An initial reduction in tumour size may be followed by a more malignant counterpart (for a review of this concept see Hockel and Vaupel ${ }^{6}$ ). It is clear, therefore, that during treatment of the neovascular consequences of uveal melanomas with anti-angiogenics, their effects on tumour growth and stability will need to be carefully monitored. In addition, recent evidence also points towards antiangiogenic therapy (in particular through blocking VEGF-A bioactivity) that serves to "normalise" tumour vasculature, which in turn promotes effective delivery of oxygen that is essential for efficacious radiotherapy. ${ }^{7}$ In short, it may be important to make use of anti-angiogenic approaches in a carefully planned and titrated manner that can enhance therapy of solid tumours.

Uveal melanomas represent a serious ocular problem and much research is needed in order to advance the established ophthalmic approaches to these 
tumours. Using fundamental laboratory and clinic based research, the angiogenic characteristics of the vasculature in uveal melanomas should be carefully determined. This is important, since residence in a highly oxygenated microenvironment such as the choroid may make uveal melanomas distinct from cutaneous counterparts. Also, recent research, indicates that the vasculature of many tumours exists in a dynamic equilibrium of mature and immature vessels and that highly malignant varieties (such as glioblastomas) have a very high ratio of immature vessels. ${ }^{5}$ This subpopulation of vessels is often the specific target of anti-angiogenic agents. This being the case, new tumour specific and tumour vasculature specific targets should be identified that can ultimately allow precisely targeted treatments, that will not significantly upset the delicate angiogenic balance that exists in many ocular tissues. Following on from this, novel delivery systems should be developed, which will allow tumours lodged in the posterior uvea to have efficacious agents delivered at appropriate concentrations while minimising risk to the non-involved retina or choroid. Efficient transcleral delivery is being researched and, if possible, may provide a approach that is particularly relevant to uveal melanomas.

Br J Ophthalmol 2002;86:368-369

\section{Authors' affiliations}

A W Stitt, T A Gardiner, Department of Ophthalmology, Queen's University of Belfast

Correspondence to: Alan W Stitt, McCauley Chair of Experimental Ophthalmology, Department of Ophthalmology, Queen's University of Belfast, Royal Victoria Hospital, Belfast BT 12 6BA, Northern Ireland, UK; a.stitt@qub.ac.uk

\section{REFERENCES}

1 Folkman J. Tumor angiogenesis: therapeutic implications. N Engl J Med 1971;285: 1182-6.

2 Warren BA, Shubik P. The growth of the blood supply to melanoma transplants in the hamster cheek pouch. Lab Invest 1966;15:464-78.

3 Cooke R. Dr Folkman's war: angiogenesis and the struggle to defeat cancer. New York: Random House, 2001.

4 Alon T, Hemo I, Itin A, et al. Vascular endothelial growth factor acts as a survival factor for newly formed retinal vessels and has implications for retinopathy of prematurity. Nat Med 1995;1:1024-8.

5 Benjamin LE, Golijanin D, Itin A, et al. Selective ablation of immature blood vessels in established human tumors follows vascular endothelial growth factor withdrawal. J Clin Invest 1999; 103:159-65.

6 Hockel M, Vaupel P. Tumor hypoxia: definitions and current clinical, biologic, and molecular aspects. J Natl Cancer Inst 2001;93:266-76.

7 Jain RK. Normalizing tumor vasculature with anti-angiogenic therapy: a new paradigm for combination therapy. Nat Med 2001;7:987-9.

\section{New BJO online submission and review system}

I am pleased to inform authors and reviewers that as of 17 April 2002, BJO will be using a new online submission and review system. Developed by Highwire Press (CA, USA), Bench $>$ Press is a fully integrated electronic system which utilises the web to allow rapid and efficient submission of manuscripts. It also allows the peer review process to be conducted entirely online. The aim, apart from saving trees, is to speed up the frequently frustrating progress from submission to publication.

Authors can submit their manuscript in any standard word processing software. Standard graphic formats acceptable are: .jpg, .tiff, .gif, and eps. (nb. multipage powerpoint files are NOT acceptable). The text and graphic files are automatically converted to PDF for ease of distribution and reviewing purposes. Authors are asked to approve their submission before it formally enters the reviewing process. On approval by the authors, the submission is passed to the editor and/or reviewers via the web. All transactions are secure.

To access the system click on "SUBMIT YOUR MANUSCRIPT HERE" on the BJO homepage: http://www.bjophthalmol.com/ or you can access Bench>Press directly at http://submit-bjo.bmijournals.com/.

We are very excited with this new development and I would encourage authors and reviewers to use the online system where possible. It really is simple to use and should be a big improvement on the current peer review process. Full instructions can be found on Bench>Press http://submit-bjo.bmijournals.com/ and BJO online at http://www.bjophthalmol.com/. Please contact Natalie Davies, Project Manager, ndavies@bmigroup.com for further information. 